\title{
Geophysical survey and geodynamic study of crust and upper mantle in the Qinghai-Tibet Plateau
}

Lithosphere Research Centre, Institute of Geology, CAGS, Beijing, 100037, China.E-mail: gaorui@cags.net.cn

\begin{abstract}
The Qinghai-Tibet Plateau, covering a vast territory and characterized by an extremely complicated structure, is considered as the ideal region to study continentcontinent collision, convergence and subduction of plates, and formation of the plateau. Since 1958, a great number of geophysical surveys have been conducted on the crust and upper mantle of the Plateau, totaling about 45,000 km in line-length. Compilation and integration of the data from these surveys has provided new summary diagrams, enabling the authors to present a review of some of the remarkable achievements over the past 50 years.
\end{abstract}

\section{Introduction}

In the process of continental evolution, continent-continent collision substantially affects the earth's structure. As a typical example, the Qinghai-Tibet Plateau, the highest, biggest and youngest orogen in the world, was brought about by collision of the Indian plate with the Eurasian plate, as well as continuous northward movement of the former. Continent-continent collision is still going on. The plateau is considered an optimal place for studying the basic problems of continental dynamics such as continent-continent collision, convergence and subduction of plates, and formation of the plateau.

Probing into the structure of the crust and upper mantle of the Qinghai-Tibet Plateau is a key to explaining continent-continent collision, and a necessary approach to understanding the forming and uplifting mechanism and geodynamic process of the plateau. Chinese geophysicists have carried out deep seismic reflection research in the Qaidam Basin in this region since the 1950s, and have acquired a wealth of scientific data.

This paper summarizes the geophysical surveys of the crust and upper mantle on the Qinghai-Tibet Plateau conducted chiefly by Chinese geophysicists, and presents a series of summary diagrams for different methods to illustrate the results. The longitudinal and latitudinal ranges discussed in this paper are $76^{\circ}-106^{\circ} \mathrm{E}$ and $26^{\circ}-40^{\circ} \mathrm{N}$ respectively, and the tectonic settings in the diagrams refer to Yin et al. (2001). On this basis, primary research results with regard to the crustal structure, electrical properties of the lithosphere, and the uplifting mechanism and geodynamical model of the plateau are reviewed. The authors hope this paper may provide valuable references for the further study of the QinghaiTibet Plateau.

\section{Status of deep geophysical survey and research}

In 1958, the Institute of Geophysics of the Chinese Academy of Science (CAS) and the Ministry of Petroleum Industry jointly detected the deep foundation bed with low-frequency seismographs, and studied the deep crustal structure in the Qaidam Basin (Zeng et al., 1961), which was the prelude of the geophysical survey of the crust and upper mantle on the Qinghai-Tibet Plateau.

\section{Deep seismic sounding (DSS)}

In 1977, CAS carried out a $460 \mathrm{~km}$-long N-S-stretching profile along the Yadong-Damxung line, and acquired information on the crustal and upper-mantle structure and velocity distribution (Institute of Geology, 1981). Since 1980, Chinese and French scientists have cooperated in conducting DSS along some sections in northern and southern Tibet and obtained abundant valuable data, which has brought about a high tide of DSS application in this region. The Ministry of Land and Resources (formerly Ministry of Geology and Mineral Resources), CAS, and the State Seismological Bureau increased their input into the DSS work. The cumulative length of DSS profiles conducted before 2004 on the Qinghai-Tibet Plateau was about $12,000 \mathrm{~km}$, and the profiles are deployed over the major part of the plateau (Figure 1).

\section{Nearly-vertical seismic reflection (Deep seismic reflection)}

Deep seismic reflection is the most effective method for studying the fine structure of the lithosphere. In 1958, Zeng and his group carried out a seismic reflection test in the Qaidam Basin, but techniques including multiple coverage and migration were not employed at that time due to the poor technical conditions (Zeng et al., 1961). The nearly-vertical seismic reflection method with multiple coverage was used for the first time by Project INDEPTH in the study of the Qinghai-Tibet Plateau. The deep seismic reflection profiles finished in this project showed fine crustal structure on both sides of the Indus-Yalu suture (IYS), which has exerted a far-reaching influence on the world. Several deep seismic reflection profiles crossing the mountain-basin junction on the northern margin of the plateau were carried out by geophysicists with the Chinese Academy of Geological Science (CAGS), which afforded an effective basis for studying the deep deformation process resulting from collision. The profiles in this plateau, however, were not intensively studied, due to high cost, and the total length of them was just $1,300 \mathrm{~km}$, about 10 per cent of that of the DSS (Figure 2). 


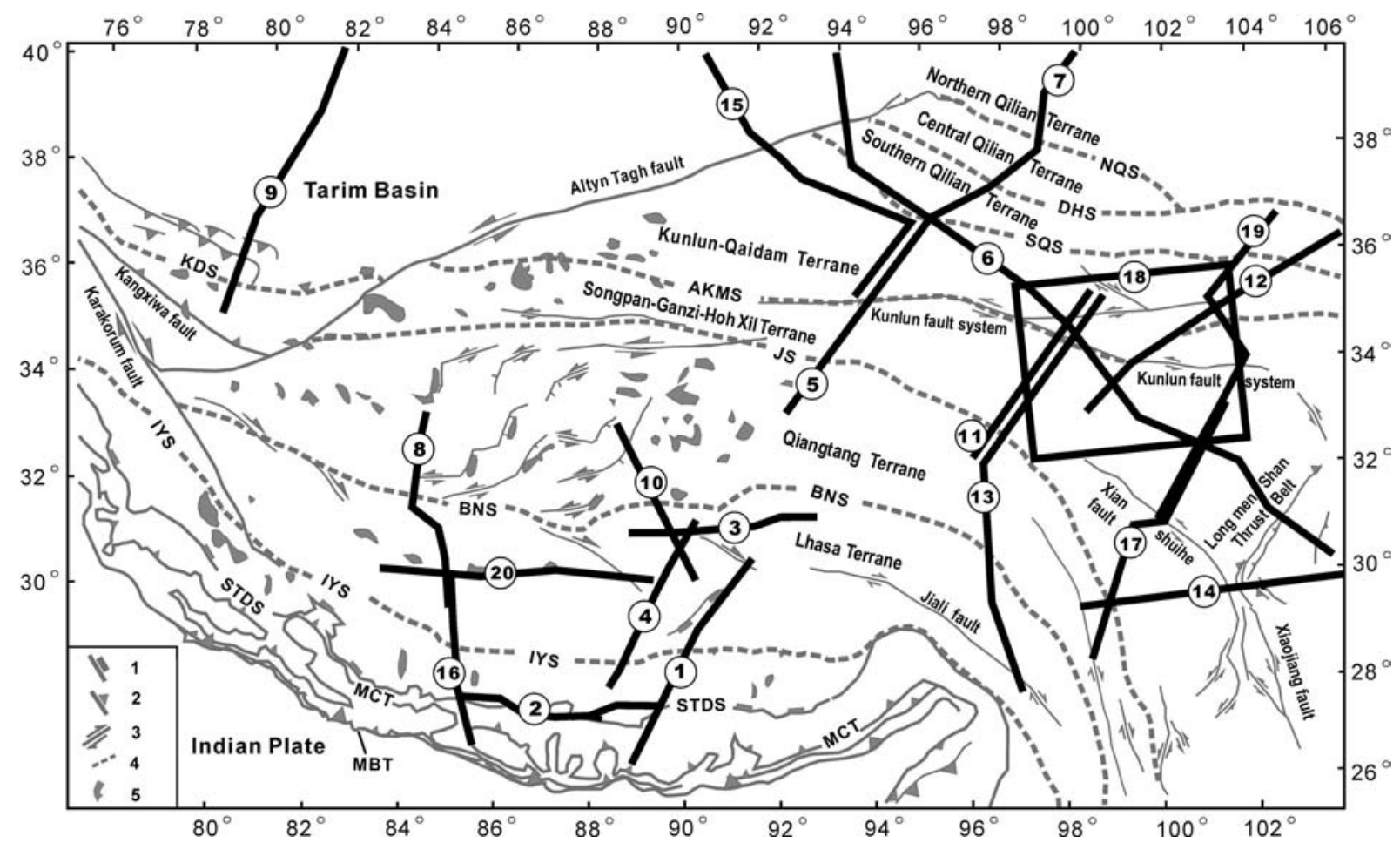

Figure 1 DSS profiles in the Qinghai-Tibet Plateau (up to 2004).

Tectonic settings (Yin A., 2001): IYS -Indus-Yalu suture; BNS-Bangong-Nujiang suture; JS-Jinsha suture; AKMS-AyimaqiKunlun-Mutztagh suture; SQS-South Qilian suture; DHS-Danghe Nan Shan suture; NQS-North Qilian suture; KS-Kudi suture; STDS_South Tibet Detachment System; MCT_Main Central Thrust; MBT_Main Boundary Thrust.

Inset: 1. normal fault; 2. thrust fault; 3. strike-slip fault; 4. suture; 5. Cenozoic high-K volcanic fields.

Seismic profiles numbering: 1. Yadong-Damxung (Institute of Geophysics, CAS, 1981); 2. Paikü Co-Puma Yumco (Teng et al., 1983; Zhang et al., 2002); 3. Siling Co-Y'angamdo (Teng et al., 1985); 4. Gala-Amdo (Xiong et al., 1985); 5. Tuotuohe-Golmud (Lu et al., 1990); 6. Aksay-Huashixia-Jianyang (Xu et al., 1993); 7. Golmud-Ejin Qi (Cui et al., 1995); 8. Cuoqin-Sangehu (Xiong et al., 1997); 9. Quanshuigou-Dushanzi (Li et al., 2001); 10. Deqing-Longwei Co (Zhao et al., 2001); 11. Gonghe-Yushu (Wang et al., 2000); 12. Dari-Lanzhou-Jingbian (Li et al., 2002); 13. Gonghe-Yushu-Xiachayu (*); 14. Batang-Zizhong (Wang et al., 2003a); 15. GolmudDa Qaidam-Mangya-Ruoqiang (Zhao et al., 2001; Zhao et al., 2003); 16. Zham-Coqen (*); 17. Tangke-Benzilan (Wang et al., 2003b); 18. 3D profile on eastern Kunlun (*); 19. Ma'erkang-Tangke-Luqu (*); 20. Eastern Silin Co-Western Coqen (*). Note: * Unpublished or in process of research.

\section{Broadband seismic observation (BB)}

In 1991, Zeng and Wu (Zeng et al., 1992) deployed 11 broadband seismographs along the Golmud-Xigazê line to observe crustal and upper-mantle structure for the first time in China. Since then, Chinese scientists have acquired a host of observation findings by means of international or regional cooperation. At the present time, this method has covered all the main sutures in this region. Triggered seismographs were first applied along the Qinghai-Tibetan Highway in the Sino-French Project in June, 1992, and improved single-component seismographs were used in 1993, which ensured high equality of data (Jiang et al., 1994). Subsequent work in the period 1995-1998 disclosed the lithospherical characteristics of the northern part of the plateau (Xu et al., 2001). Broadband seismic observation in the INDEPTH crossed the Bangong-Nujiang suture (BNS) and entered the Qiangtang block, so as to deepen the research on the deformation mechanism of the interior structure of the plateau. During the period 1997-1998, the CAGS and the Institute of Earth Sciences, Academia Sinica based in Taiwan jointly studied the deep structure of the Tarim and western Kunlun region with the TEFTEK-72 digital acquisition system, STS-II broadband receiver and GPS equipment. This program detected hundreds of effective seismic events and acquired dozens of gigabytes of data (Kao et al., 2001) (Figure 3).

\section{Magnetotelluric sounding (MT)}

Magnetotelluric sounding is a natural-source electromagnetic method, which takes surface electromagnetic waves as the field source, and traces underground records by observing quadrature electromagnetic components. The MT has proved successful in studying continental dynamic problems. During the period 1980-1981, a Sino-French team applied this method for the first time to the study of the Qinghai-Tibet Plateau (Yuan et al., 1990). Two MT sections, the Yadong-Golmud and Golmud-Ejin Qi global geological transects (GGTs), traversed the whole plateau and revealed its electrical structure (Guo et al., 1990; Zhu et al., 1995). The INDEPTH-MT research team, composed of Chinese and American geophysicists, observed long-period and broadband magnetotelluric fields as a whole by means of 21 long-period observation instruments, LIMS (period of signal acquisition: 10 300,000 s) and a broadband instrument (period of signal acquisition: 1/320-2,000 s) (Wei et al., 2001). Appropriate observation methods and high-precision equipment greatly enhanced the quality of the acquired data. The MT profiles accomplished thus far run through the Qinghai-Tibet Plateau from north to south, and have laid a solid foundation for studying the electrical structure of the whole plateau. By 2004, the cumulative length of MT profiles was more than 10,000 km (Figure 4).

\section{Deep gravity and magnetic surveys}

Deep gravity and magnetic surveys are very important approaches to examining the crustal structure and uplifting mechanism of the Qinghai-Tibet Plateau. Both of these surveys were conducted during the study of the Yadong-Golmud and Golmud-Ejin Qi GGTs. The total lengths of deep gravity and magnetic sections completed from 1982 to 2004 were more than $8,300 \mathrm{~km}$ and $5,800 \mathrm{~km}$ respectively (Figure 5). 


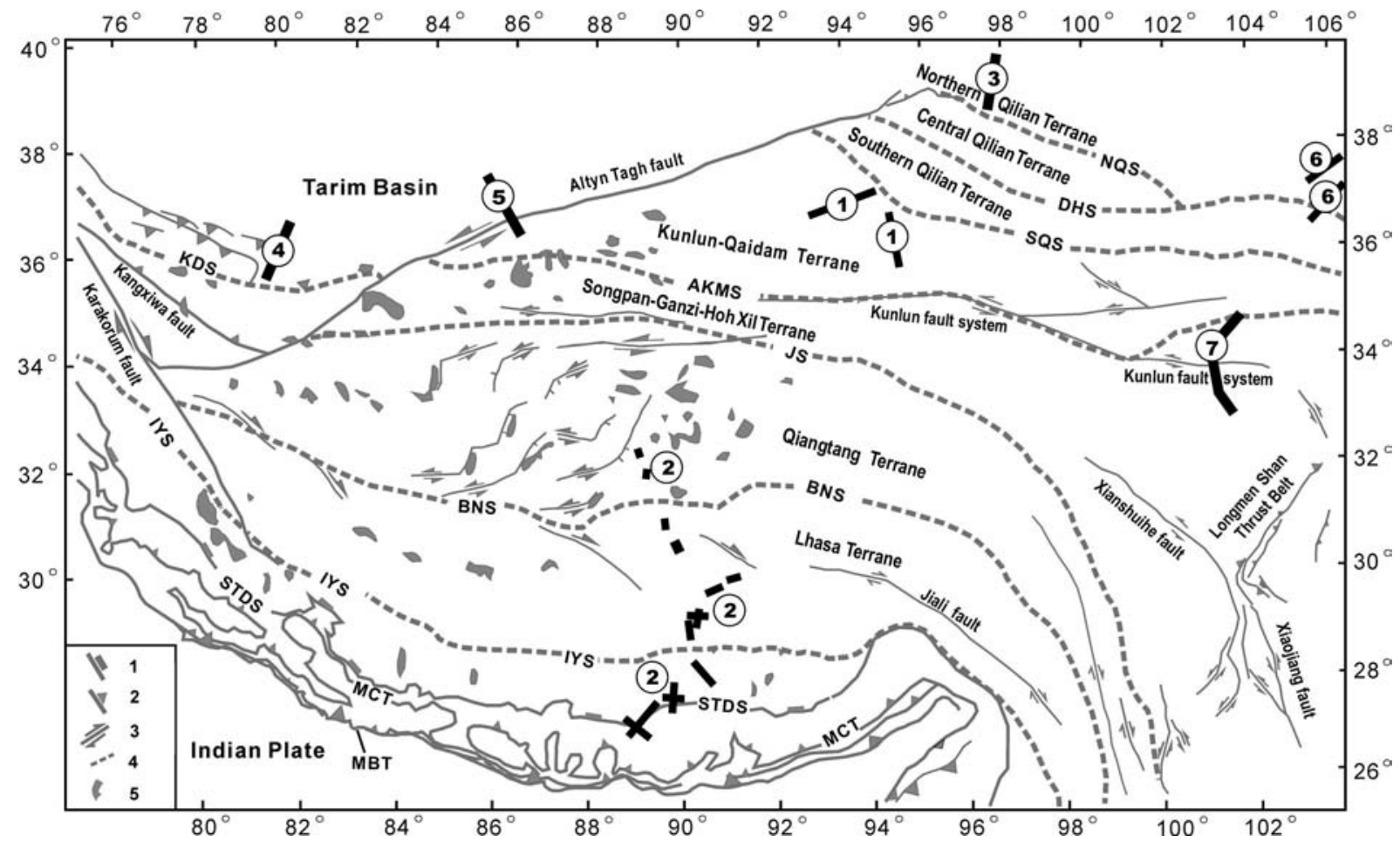

Figure 2 Deep seismic reflection profiles on the Qinghai-Tibet Plateau (up to 2004).

Tectonic settings the same as in Figure 1. Profiles numbering: 1. Yuka-Gansen, Golmud-Da Qaidam (Zeng et al., 1961); 2. INDEPTH

Project (Zhao et al., 1993; Zhao et al., 1997); 3. Diaodaban-Huahai (Wu et al., 1995); 4. Cele-Qimankarouke (Gao et al., 2000); 5. Tugaisulake-Qiemo-Luoyeshan (Gao et al., 2001); 6. Jingyuan-Xinzhuangji and Tongxin-Wangxinzhuang (*); 7. Hezuo-Tangke (Gao et al., 2005)

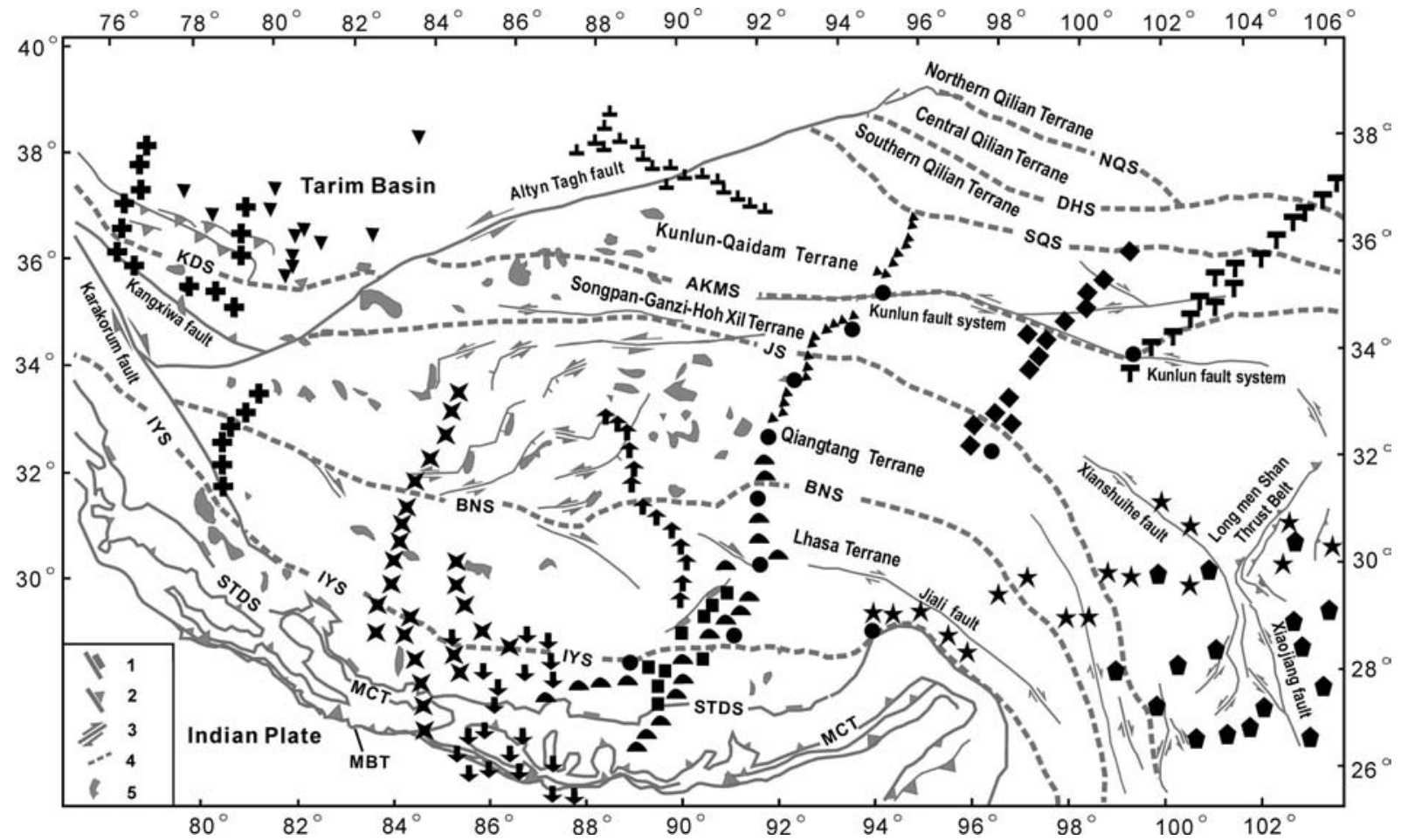

Figure 3 Locations of broadband seismic stations on the Qinghai-Tibet Plateau (up to 2004).

Tectonic setting the same as in Figure 1. Broadband seismic stations: $\bullet$ Golmud-Xigazê (Zeng et al., 1992); - Tanggula-Dingri (Lü et al., 1996); $\triangle$ Tanggula-Golmud Xitieshan (Jiang et al., 1996); $\square$ Samada-Namu Co (Kind et al., 2002); $\perp$ Mangya-Ruoqiang (Shi et al., 1999); - Xikunlun-Tarim (Kao et al., 2001); $\$$ Gonghe-Yushu (Qian et al., 2001); $\uparrow$ Deqing-Longwei Co (Tilmann et al., 2003; Zhao et al., 2004); + Yecheng-Shiquanhe (Xue et al., 2004); TYulin-Maqin (Guo et al., 2004); + Nepal-Himalayas (Pelkum et al., 2005); - Western plateau of Sichuan (*); $\times$ India-Nepal-Western Tibet $(*) ; \star$ Eastern wedge of the Tibetan plateau (*). Note: *Unpublished or in process of research. 


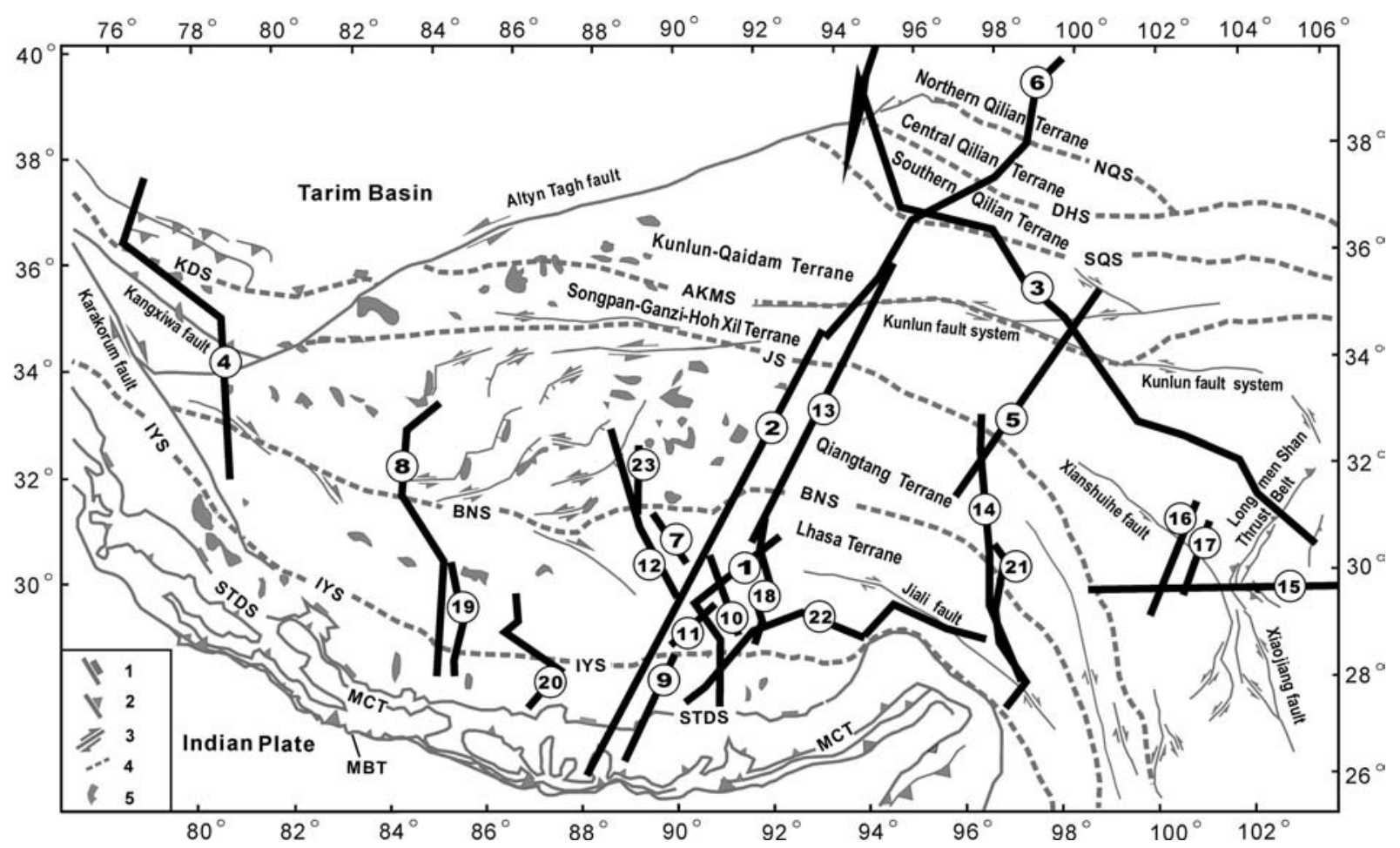

Figure 4 MT profiles on the Qinghai-Tibet Plateau (up to 2004).

Tectonic setting the same as in Figure 1. Lines numbering: 1. Lhozhag-Nagqu (Yuan et al., 1990); 2. Yadong-Golmud (Guo et al., 1990); 3. Altay-Taiwan (*); 4. Yecheng-Shiquanhe (Qin et al., 1994); 5. Nangqian-Qinghai (*); 6. Golmud-Ejin Qi (Zhu et al., 1995); 7. Lunpola (*); 8. Jilong-Coqen-Sangehu (Ma et al., 1997); 9-13. INDEPTH-MT (Chen et al., 1996; Wei et al., 2001); 14. Qingshuihe-Zayu (Maet al., 2001); 15. Batang-Zizhong (Sun et al., 2003); 16. Daocheng-Guanyinqiao (Sun et al., 2003 ); 17. Xinduqiao-Andingxiang (Sun et al., 2003); 18-22. Line700-Line 2000 (Tan et al., 2004); 23. Qiangtang Basin (*). Note: *Unpublished or in process of research.

\section{Heat flow observation}

Discussion and study of the deep thermal regime of terranes, thermal structure of the crust and mantle and formation of the Qinghai-Tibet Plateau are the key to disclosing the uplifting mechanism of the plateau. In this regard, the heat flow observation serves as an indispensable geophysical approach, having been employed in the survey of the Yadong-Golmud and Golmud-Ejin Qi GGTs (Shen et al., 1990; 1995). This work has revealed the heat flow distribution, deep geo-thermal regime, thermal structure of the crust and mantle, and lateral heterogeneity and formation mechanism of the plateau (Figure 6).

\section{Major achievements of geophysical surveys of crust and upper mantle in the Qinghai-Tibet Plateau}

\section{Crustal structure}

Deep geophysical surveys have covered the main structure units of the Qinghai-Tibet Plateau since 1958. They cross the Himalayas, west Kunlun-Altyn-Qilian Mountains and Longmen Mountains. The profiles have a total length of about $45,000 \mathrm{~km}$, and have disclosed the 3D structure and structural frame of the crust and upper mantle of the plateau.

\section{Moho depth and its changes}

The Moho depth is a significant indicator of crustal structure. The great thickness of the Qinghai-Tibet Plateau is unique in the world. So far, seismic methods have been used to explore the Moho depth, among which DSS is the most effective one. We usually use $\mathrm{Pm}$ and Pn wave phases to ascertain the Moho depth, and the P wave velocity at the top of the upper mantle. The Pn wave phase, however, is not easily observed in the interior of the plateau. Geophysical researches throughout the world show that strong response to the Moho can be obtained in terms of deep seismic reflections.

The lower crust often appears as a compressional reflection layer beneath an orogenic zone, while the bottom of the layer corresponds with the refraction Moho. The broadband seismic observation has been developing rapidly and made great progress on the Qinghai-Tibet Plateau. P wave conversion (e.g. P-S conversion) while passing the Moho can be recorded by broadband seismic stations. The Moho depth and configuration are imaged with the receiver function method. Detailed changes of the Moho can be detected by deep seismic reflection, the resolution of which is higher than that of the DSS. Researches conducted extensively worldwide show that the results of these two methods can be correlated in general. Resolution of the broadband seismic observation is lower than those of the deep seismic reflection and DSS. However, the receiver function method and the reflection method have a similar theory. Converted waves from teleseismic events are fairly sensitive to the location of the Moho surface. Research findings reported both in China and abroad show that the broadband seismic method and the DSS present almost consistent images of the Moho along the section from Lhasa to Golmud. Our discussion on the Moho depth and its changes are right based on this understanding.

\section{a. The deepest and shallowest Moho}

The latest broadband seismic observation reveals that the deepest Moho in the Qinghai-Tibet Plateau is located at the west Kunlun structural knot $(90 \pm 2 \mathrm{~km}$ in thickness) beneath the southern branch of the Altyn fault (Wittlinger et al., 2004). Gao et al. (2005) accomplished a deep seismic reflection profile crossing the west Qinling orogen and the Zoigê basin, and discovered a strong reflection of the Moho at $16.50 \mathrm{~s}$ TWT (two-way travel time), corresponding to a depth of approximately $49.50 \mathrm{~km}$, which may be considered the shallowest Moho in this region. 


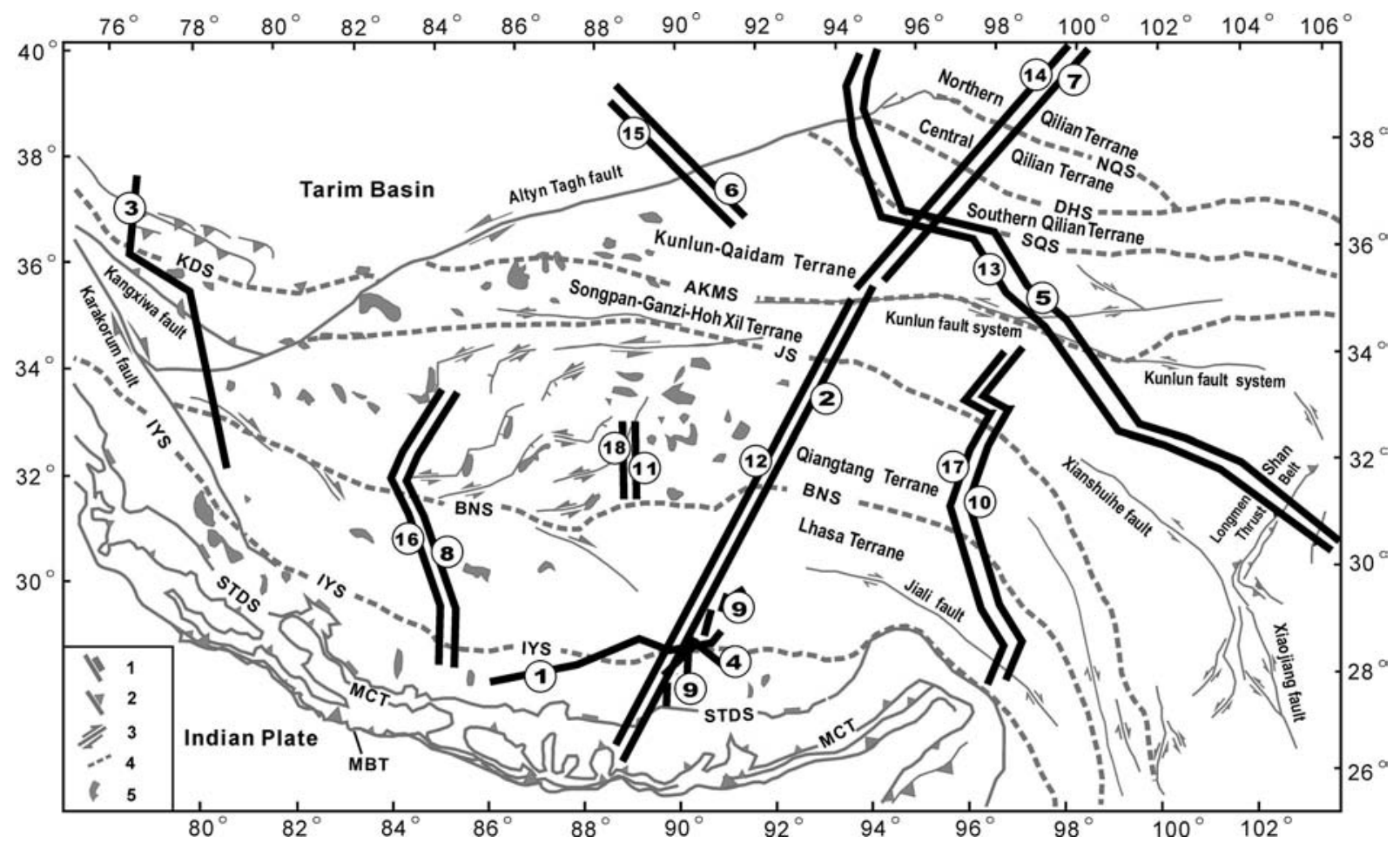

Figure 5 Gravity and magnetic profiles on the Qinghai-Tibet Plateau (up to 2004).

Tectonic settings the same as in Figure 1. Lines numbering (1-11-gravity survey, 12-18-magnetic survey): 1. Yangbajing-Nielamu (Meng et al., 1984); 2. Yadong-Golmud (Meng et al., 1990a); 3. Yecheng-Xishiquanhe (Meng et al., 1990b); 4. Nimu-Dongla (Lithosphere Research Center, CAGS, 1996); 5. Altay-Taiwan (*); 6. Aergan-Laomangya (Meng et al., 1998); 7. Golmud-Ejin Qi (Meng et al., 1995); 8. Jilong-Lugu-Sangehu (Wang et al., 1997); 9. INDEPTH project (*); 10. Maduo-Yushu-Xiachayu (Wang et al., 2001); 11. Qiangtang Basin (*); 12. Yadong-Golmud (Yu et al., 1990); 13. Altay-Taiwan (*); 14. Golmud-Ejin Qi (Yu et al., 1995); 15. Aergan-Laomangya (Meng et al., 1998); 16. Jilong-Lugu-Sangehu (*); 17. Maduo-Yushu-Xiachayu (Liu et al., 2001); 18. Qiangtang Basin (*). Note: * Unpublished or in process of research.

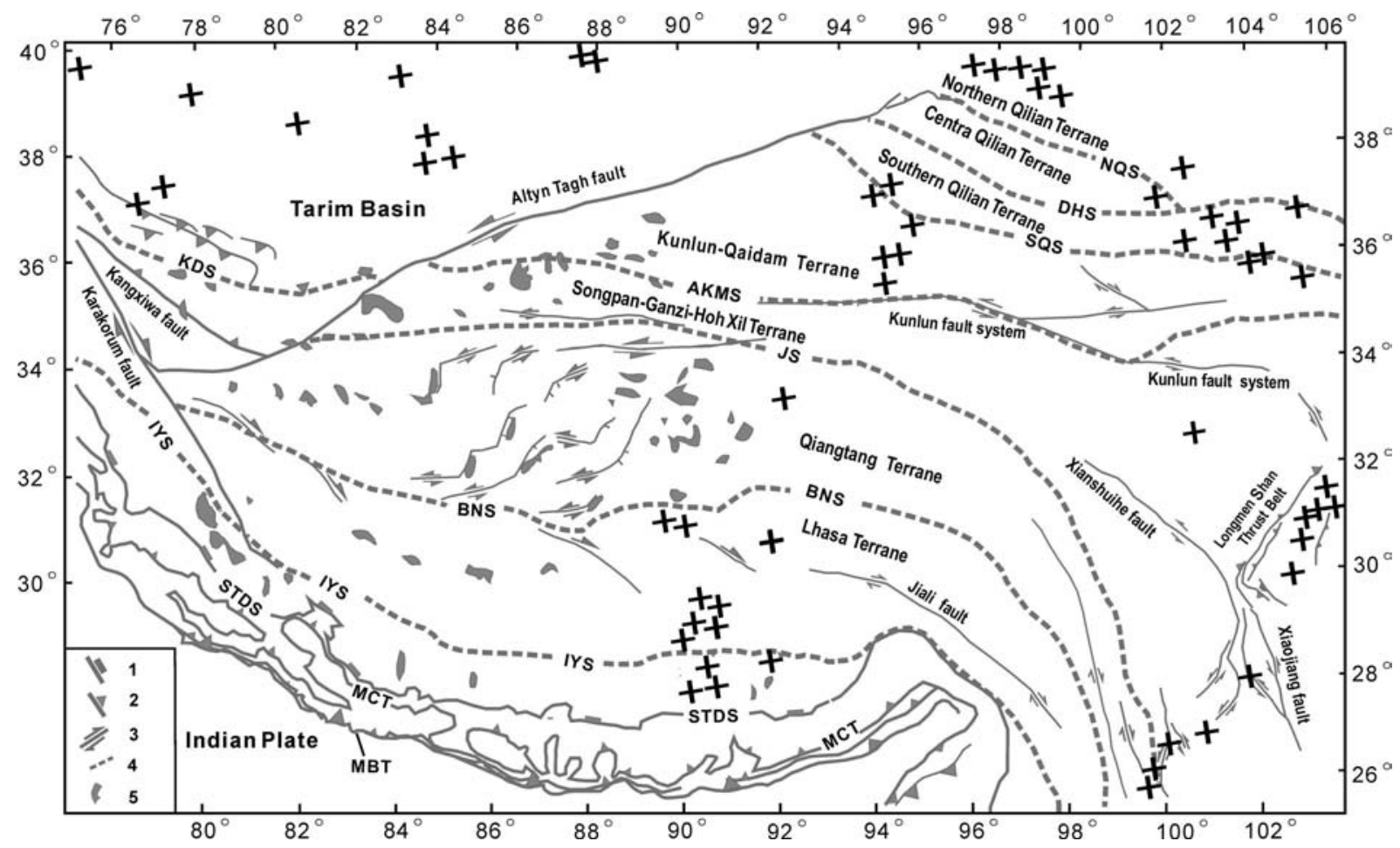

Figure 6 Heat flow survey on the Qinghai-Tibet Plateau (up to 2004).

Tectonic settings the same as in Figure 1. + Location of geothermal survey. 
b. Variation of the Moho across the plateau from north to south

Scientists have paid great attention to the changes of the Moho from north to south across the Qinghai-Tibet Plateau. Xiong et al. (1985) and Hirn et al. (1984) studied such changes by using the data obtained by the Sino-French research project (1981-1982). Afterwards, some new probe sections were finished in northern Tibet. To summarize, the Moho is shallow on the northern and southern margins of the plateau, and deep in the central part. Besides, offsets can be observed on both sides of the main sutures (Figure 7).

To date, no completed active-source seismic profile has been done for the purpose of investigating crustal thickness, so the Moho depth and its changes beneath the Himalayas are still unclear. The Sino-French team suggested a depth of $55-53 \mathrm{~km}$ for the Moho beneath the high Himalayan organic belt, with a gentle rise in its northern part. They gave this estimate based on the records along a profile with the shotpoint in Tibet and the receiver in Nepal (Xiong et al., 1985). The INDEPTH-I seismic reflection profile gave a Moho depth of $75 \mathrm{~km}$. With its southern end at Pagri, this profile crosses the high peak region of the Himalayas, so $75 \mathrm{~km}$ may indicate the largest depth of the Moho under the Himalayas (Zhao et al., 1993). However, there exist high-Himalayan crystalline rocks on the southern slope of the Himalayas, and therefore some geophysicists think that the depth of $75 \mathrm{~km}$ is consistent with the value of $75-78 \mathrm{~km}$ obtained by the Sino-French Project along the Paikü Co-Puma Yumgco profile (Teng et al., 1983; Xiong et al., 1985). Pelkum et al. (2005) considered that the Moho depth is $\sim 45 \mathrm{~km}$ from Nepal to the southern high Himalayas and reaches $\sim 75 \mathrm{~km}$ beneath the Tethyan Himalayas.

The Moho is offset beneath the IYS suture. Hirn et al. (1984) proposed a larger offset $(\sim 20 \mathrm{~km})$, while Xiong et al. (1985) suggested a smaller offset $(\sim 10 \mathrm{~km})$.

The Moho depth under the Lhasa block has been a disputable question for a long time. Some have concluded that the average Moho depth of the Lhasa block is $55 \mathrm{~km}$ (Hirn et al., 1984), but others estimated the value at $70 \mathrm{~km}$ (Xiong et al., 1985). After reinterpreting the Siling Co-Y'angamdo wide-angle seismic profile, Zhang et al. (2001) hypothesised a downwarping form of the Moho in northern Tibet, and thought the depth to be at least $80 \mathrm{~km}$. To the south of BNS, the Moho is reportedly as deep as 80-84 km (Zeng et al., 1994). Unfortunately, the INDEPTH-II seismic reflection profile was not able to detect the Moho under the Lhasa block.

The Moho is also offset as crossing the BNS, and becomes shallower upon entering the Qiangtang block. Wideband seismic observation revealed a Moho offset of $\sim 10 \mathrm{~km}$ (Zeng et al., 1994), but the INDEPTH-III presented a value of only $5 \mathrm{~km}$ (Ross et al., 2004). Despite the disagreement, it should be commonly accepted that the Moho becomes shallower when it crosses the BNS.

Beneath the northern Qiangtang block along the TuotuoheGolmud wide-angle seismic profile, the Moho has a depth of 68-70 $\mathrm{km}$ (Lu et al., 1990) and a small offset, $60 \mathrm{~km}$, under the Jinshajiang suture (Li et al., 2004a). From the eastern Kunlun Mountains to the Qaidam Basin, the Moho depth undulates in a range from $60 \mathrm{~km}$ to $52 \pm 2 \mathrm{~km}$ (Lu et al., 1990). The Moho offset does not exceed $10 \mathrm{~km}$, which is close to the finding by Wu Q.J. et al. (1998), but obviously different from the value of 15-20 km estimated by Zhu et al. (1998). The difference is aroused by the disagreement with respect to the Moho depth in the Qaidam block. Blasting seismic profiles across the Qaidam Basin present an average Moho depth of 55-60 km (Xu et al., 1993; Cui et al., 1995; Zhao et al., 2001), but merely $40 \mathrm{~km}$ was the Moho depth in the model proposed by Zhu et al. (1998). The Golmud-Ejin Qi transect (1990-1995) revealed a Moho depth of $60-70 \mathrm{~km}$ under the Qilian Mountains, $57 \mathrm{~km}$ on the northern margin of the Qilian Mountains and 48-52 km in the Hexi Corridor basin (Cui et al., 1995).

\section{c. Variation of Moho in the nearly east-west direction}

Though there is a limited number of east-west deep seismic survey sections in the Qinghai-Tibet Plateau, we can still qualitatively describe the east-west changes of the Moho depth in this area. The existing data suggest that the Moho is deeper in the west and shallower in the east. This is probably related to the eastward flow of the matter out of the plateau.

\section{Depth and characteristics of low-velocity and high- conductivity layers in the crust}

Low-velocity and high-conductivity layers occur extensively but discontinuously in the Tibetan crust, with a depth of $20 \pm 5 \mathrm{~km}$, a velocity of $5.6-5.8 \mathrm{~km} / \mathrm{s}$ and a thickness of $5-10 \mathrm{~km}$. Though not exactly coincident with each other, they have a similar variation trend in depth and thickness (Gao et al., 1995).

There are different opinions on the formation of the layer. Nelson et al. (1996) concluded that a partial-melting layer existed broadly in the middle crust beneath southern Tibet. Notably, where low-velocity zones are recognised, partial melting is manifest. Kind et al. (1996) agreed with this viewpoint. Wang et al. (1990) hold that the mid-crustal low-velocity layer beneath southern Tibet may be a brashy zone composed of partially-melting matter, which formed a detachment surface in the mid-crust where most surficial faults are terminated. Spratt et al. (2005) considered that the high-conductivity layer originated from partially-melting matter in northern Tibet, whereas Wei et al. (2001) reported that this layer is probably due to both partial melting and fluids in southern Tibet.

\section{Characteristics and types of velocity structure in the lower crust}

Thickening of the lower crust in the Qinghai-Tibet Plateau is influenced by heterogeneity of the crust. We can divide the lower crust into several types, as below, in terms of velocity structure and reflection characteristics obtained with DSS and deep seismic reflection profiles.

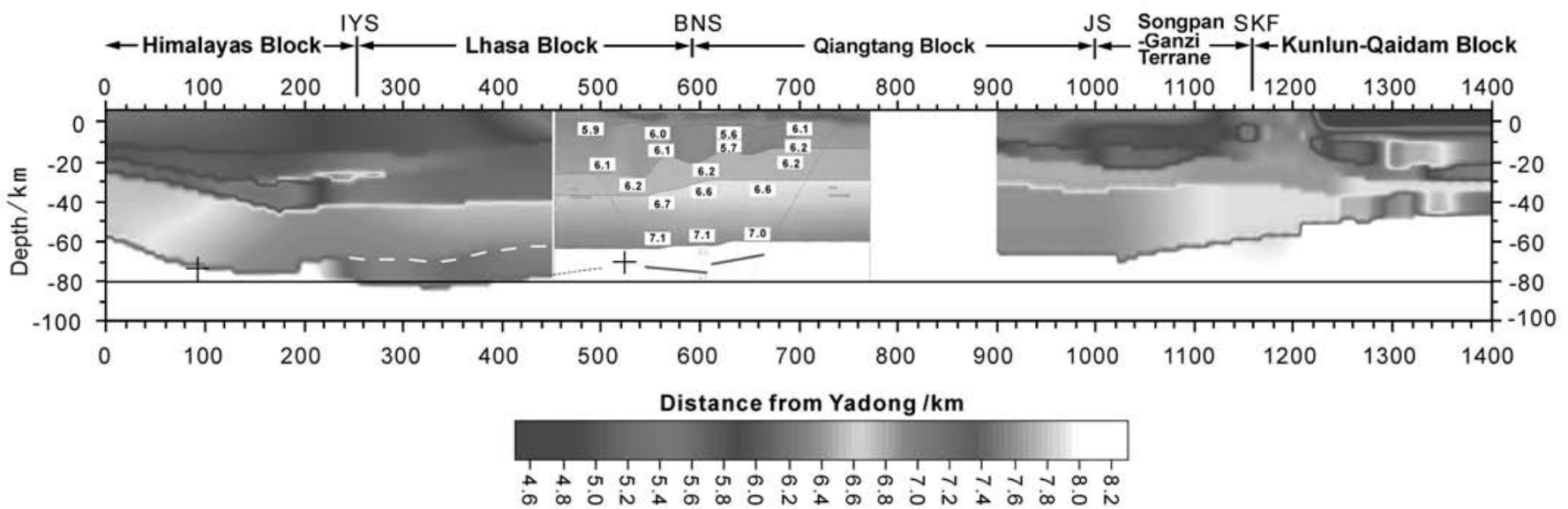

Figure 7 Variation of the Moho when crossing the plateau from north to south. (After Li et al., 2004b) 
a. Lower crust with reverse velocity structure. The Yadong-Golmud GGT depicts a reverse velocity structure, which is characteristic of the lower crust under the Tethyan Himalayan orogen, where seismic waves are reversed extensively (Wu et al., 1991). Such a lower crust is $38-78 \mathrm{~km}$ in depth, with a thickness of 40 $\mathrm{km}$;

b. Lower crust with graded velocity structure. Wang et al. (1990) reported lower crust with graded structure of velocity in northern Tibet. The gradient belt he estimated is $20-30 \mathrm{~km}$ thick and $55-82 \mathrm{~km}$ deep in the lower crust, with an average velocity of $7.40 \mathrm{~km} / \mathrm{s}$. There is a great dispute on whether the Moho depth is $50 \sim 56 \mathrm{~km}$ or $70 \sim 75 \mathrm{~km}$, because of the disagreement on the velocity gradient belt of $7.4 \mathrm{~km} / \mathrm{s}$. The belt with this velocity was classified as the lower crust, based on the correlation between reflection and refraction waves in the study of the Yadong-Golmud GGT (Wu et al., 1991). A similar phenomenon can be seen in the Kunlun structural belt (Lu et al., 1990);

c. Lower crust with multilayer close reflections. Lower crust with close reflection has been widely discovered beneath orogens throughout the world. Strong reflectivity was found at $10 \mathrm{~s}-20 \mathrm{~s}$ on the Bangoin deep seismic reflection profile studied in the third phase of the INDEPTH (INDEPTH-III), which resembles the typical reflectivity in the lower crust along the BIRPS WAM line in Western Europe (Ross et al., 2004). Gao et al. (2005) interpreted the strong reflection layer at $7 \mathrm{~s}$ on the Songpanwestern Qinling reflection profile as the lower crust (Figure 8);

d. Thinning lower crust. A number of facts have been noticed, such as the shallowing of the Moho $(65-58 \mathrm{~km})$ when crossing the BNS, low velocity of Pn waves in the Qiangtang block (McNamara et al., 1995), great attenuation of Sn waves and large-scale high-conductivity zones. All these imply that the lower crust is structurally thinning, and a mass of heat flows are existing in the region (Wei et al., 2001);

e. Steady platform lower crust. Based on the study in the eastern Qaidam Basin, Teng et al. (1974) discovered a steady high-velocity layer near the Moho, and he considered it to be steady basic matter in the lower crust under the Qaidam Basin (Figure 9).

\section{Uncertainty of lithosphere thickness}

Seismic methods serve as the principal means for geophysical investigations, but they need super-long profiles, usually over 1,000 $\mathrm{km}$, to study the lithosphere. Up to now, active-source seismic

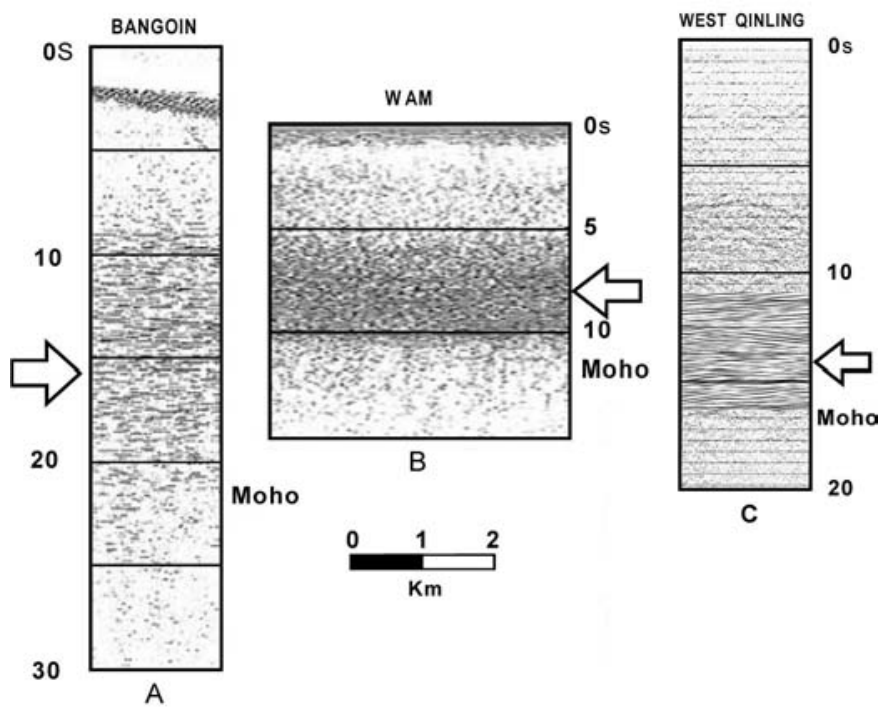

Figure 8 Intensive reflection in the lower crust. (Modified from Ross et al., 2004) A-Bangoin line in INDEPTH-III; B-BIRPS WAM line; $C-$ West Qinling Line.

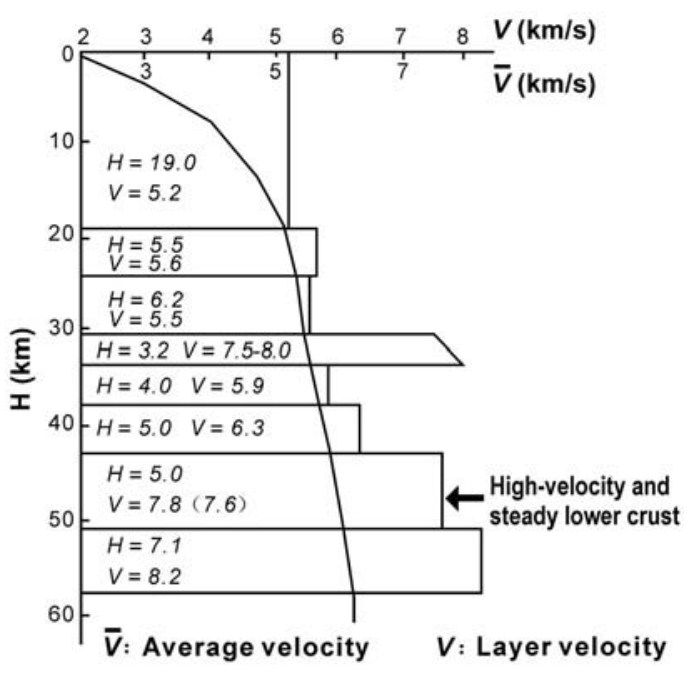

Figure 9 Crustal velocity structure of Qaidam Basin (After Teng et al., 1974)

methods have not yielded helpful information on lithospheric thickness in the Qinghai-Tibet Plateau, due to complexity of the crustal structure. At present, natural earthquake data are used as primary information in this respect. Song et al. (1985) assumed that the thickness of the Tibet plateau was $120 \mathrm{~km}$, the same finding was obtained by Zhuang et al. (1992). Chen et al. (1985) reported 100 $\mathrm{km}$ by means of the surface wave dispersion of frequency, and $\mathrm{Wu}$ J.P. et al. (1998) gave a thickness of $110 \mathrm{~km}$ based on body wave inversion. The difference among these findings is brought about by different seismic wave traces, different data and different operation methods. However, natural earthquake records probably suggest that the lithospheric mantle is not quite thick, in spite of the extreme thickness of the crust.

Geophysicists usually infer lithospheric thickness based on the thickness and variation of high-conductivity layers in the upper mantle acquired by the MT, which has been employed to study the depth and undulation of the upper mantle under the Qinghai-Tibet Plateau. Discussions and descriptions of the lithospheric thickness were made during the Sino-French Project and in the study of the YadongGolmud GGT (Guo et al., 1990). However, the reliability of the information about the deep structure is somewhat weakened due to lack of measuring points, large spacing of the points and narrow frequency band of the MT. Nevertheless, the above study can still be regarded as successful under the poor working conditions of that time.

The broadband magnetotelluric system (MT24) and the superlong-period MT system (LIMS) were used together to collect superlong-period magnetotelluric signals. The electrical structure of the crust and mantle beneath the plateau was described with modern MT data-processing and inversion techniques (Chen et al., 1996; Wei et al., 2003; Tan et al, 2004; Spratt et al., 2005). The INDEPTH-MT team did not find high-conductivity layers in the upper mantle. The low-resistivity layer in the upper mantle lies at a great depth in the Himalayan orogen in southern Tibet, while the low-resisitivity layer in the asthenosphere is upwarped beneath the Gangdisê structural belt in Central Tibet, which implies fine regional conductivity. Presently, none of the published INDEPTH-MT findings has specified the exact thickness of the lithosphere in the Qinghai-Tibet Plateau.

It can thus be seen that seismic methods as well as the MT sounding method cannot accurately decide the lithospheric thickness of the Qinghai-Tibet Plateau, suggesting that the lithospheric thickness of the plateau is uncertain. 


\section{Uplift mechanism and geodynamic process of the Qinghai-Tibet Plateau}

The formation and uplift mechanism of the Qinghai-Tibet Plateau is a complex question. Despite a considerable body of research, there are still diverse opinions (Gao, 1997; Pan, 1999).

\section{Amalgamation of terranes and uplift of the plateau}

Chinese geologists discussed the forming process of the Qinghai-Tibet Plateau at a fairly early date. Chang et al. (1982) argued that the plateau was not a uniform body, but came into being as an assemblage of terranes of diverse periods. This viewpoint was supported by geophysical surveys (e.g. Wu et al., 1991; Gao et al., 1995).

Wu et al. (1991) pointed out that the plateau kept uplifting in the course of terrane amalgamation, which underwent a process of "ocean-crust underthrusting $\rightarrow$ continent-continent collision $\rightarrow$ intracontinent underthrusting". Ocean-crust underthrusting induced thickening of continental crust, and continent-continent collision gave rise to thrusting and overlapping of slabs, thus thickening the crust. The intracontinent underthrusting taking place after continentcontinent collision was perhaps due to gravitational sinking of oceanic lithospheric plates or continental inserting along crustal weak zones. It was assumed that inhomogeneous uplift occurred as early as when terranes were assembled to form the Qinghai-Tibet Plateau, which was actually confirmed by a subsequent research (Murphy et al., 1997). After the plateau was formed, the crust slid along terrane boundaries under persistent bidirectional extrusion of the Indian and Asian plates. North-south shortening and east-west extension of the crust were absorbed by active old sutures and NE- and NW-stretching strike-slip faults developed in the terranes.

$\mathrm{Li}$ (1995) summarised the uplift mechanism of the plateau as "intracontinental converging $\rightarrow$ layering thickening of crust $\rightarrow$ gravitational isostatic adjustment". Northward continuous move of the Indian plate and obstruction of the surrounding rigid blocks brought about violent intracontinental convergence. Affected by strong compressing stress, intracontinental underthrusting took place along old sutures between structural belts; on the other hand, there took place multiple detachment in the crust. The upper, middle and lower crust became either thicker or shorter in different ways. The plateau uplifted slowly, and the upper mantle subsided greatly, thus forming a "mountain root". During the Pliocene and Middle Pleistocene, especially the latter, the plateau drifted more slowly on the whole, and the differences in drift velocity of different blocks became less significant. As a result, stress was relaxed and press reduced. Strong isostatic readjustment was then reached under the influence of the mountain root. In this case, the whole plateau was uplifted considerably and quickly, eventuating on the huge Qinghai-Tibet Plateau.

Zhong et al. (1996) considered the uplift of the plateau a multistage, speed-variable and inhomogeneous process. At least two mechanisms are responsible for the entire uplift and local rapid rise of the plateau since the Late Pliocene.

According to the $3 \mathrm{D}$ velocity structure of the Rayleigh wave and the result of the DSS, Teng et al. (1999) put forward a model of two-layer "wedge plates", that is, the crust and upper mantle of the Indian plate was blocked by various tectonic bodies while moving northwards and finally terminated at different positions. The first "wedge plate" is the middle and upper crust, where the matter above the Moho moves northwards and is obstructed by steep faults around the Yarlung Zangbo River. The second "wedge plate" is at the bottom of the low-velocity layer above the Moho, and the top of the mantle low-velocity layer as its upper and lower detachment surfaces. Pushed by a strong collisional and compressional system, it moved northwards, breaking through the Yarlung Zangbo fault, and stopped at the southern margin of the Tarim-Qaidam terrane when obstructed by the northern continental core.

Based on four seismic tomographic profiles across the QinghaiTibet Plateau, 3D travel-time data and transformed waves, $\mathrm{Xu}$ et al. (2004) obtained seismic wave anisotropy, seismic velocity layers and velocity images of layers from surface down to a depth of $400 \mathrm{~km}$, which demonstrate the structural and physical characteristics of the mantle. Furthermore, a new collisional model for the Qinghai-Tibet Plateau was proposed, which involved the following geological events: ultradeep intracontinental subduction of the Indian lithosptheric slab in the southern plateau, deep subduction of the craton on the northern margin, deep mantle plume in the interior, and "dextral uplift" and eastward extrusion of material beyond the lithosphere.

\section{Lithospheric detachment and slab abruption}

Bird (1978) put forward a detachment mode on the basis of heat sources of collision and orogeny, and discussed the granite magmatism, metamorphism and uplift mechanism of the Himalayan orogen. Detachment caused descending of the lithospheric mantle and ascending of asthenosphere, followed by material exchanges between the lower crust, lithospheric mantle and asthenosphere, and consequently magmatism, uplift of mountains, and extension and collapse took place. Geophysical surveys can be an effective approach to yielding information on lithospheric detachment on the plateau.

Based on seismic tomographic images, Kosarev et al., (1999) held that the north-plunging Indian lithospheric mantle began to detach from the crust $50 \mathrm{~km}$ north of the Indus-Yalu suture. The lithospheric mantle kept undertrusting northwards, met with the Asian lithospheric mantle $50-100 \mathrm{~km}$ north of the BNS at depths of $200-250 \mathrm{~km}$, and then subsided beneath the mantle. Mass transfer might have occurred at the boundary of the irregular $410-\mathrm{km}$ discontinuity beneath northern Tibet. Kind et al. (2002), in terms of the same technique, proved the underthrust of the south-dipping Asian lithospheric mantle toward the Qiangtang block. Tilmann et al. (2003) reported that the front of the Indian lithospheric mantle was detached $100 \mathrm{~km}$ below the Qiangtang block, where a mass of asthenospheric matter ascended and was exchanged with the lithosphere.

Zeng et al. (2000) observed multiple crustal subductions in the Himalayas and southern Tibet. The subducting Indian crust must have split apart from its upper mantle, and the Indian lithospheric mantle subducted continuously in the upper mantle, which can be showed by geophysical evidence (Wu et al., 2004). Xu et al. (2004) reported that the Indian lithospheric slap subducted gently $400 \mathrm{~km}$ north of the IYS, beneath the Tanggula mountains. A large highvelocity anomalous zone was split into separate high-velocity anomalous bodies, which may be considered as geophysical evidence for abruption brought about by Indian lithospheric mantle subduction.

\section{Conclusions}

Thanks to the efforts made over the past fifty years, geophysicists have carried out numerous projects on the Qinghai-Tibet Plateau, studying the crust and upper mantle. The total length of the accomplished survey profiles has already amounted to more than 45,000 $\mathrm{km}$. These projects have provided convincing geophysical evidence for the study of many interesting questions about the plateau such as the formation process, lithosphere structure and uplift mechanism.

(1) In general, the crust of the Qinghai-Tibet Plateau is thinner in its southern, northern and eastern parts, but thicker in the western part, with asymmetrical thickening revealed in the central part. The thickest crust is found in the Tethyan Himalayan structure belt, while the thinnest is located in the Zoigê block in northeastern Tibet. The Moho is offset more or less when crossing all the main sutures. There are distributed nonuniform low-velocity and high-conductivity layers or structural detachment layers in the crust of all the terranes. It is hard to ascertain the thickness of the lithosphere for the time being. Although the crust is extremely thick, no evidence has been found for the thickening of the lithospheric mantle. 
(2) The lower crust of the Qinghai-Tibet Plateau is characterised by inhomogeneous structure, exhibited in different forms: reverse velocity structure in southern Tibet, graded velocity structure in northern Tibet, and lower crust with multi-layer close reflections, thinning lower crust and steady platform lower crust. Different types of structure are related to different behaviours of crustal activity.

(3) The Qinghai-Tibet Plateau is a nonuniform body composed of terranes possessing diverse development processes. Actually, inhomogeneous uplift already occurred in the course of terrane amalgamation. Bi-directional convergence and compression of the Indian plate and the Eurasian plate was the major driving force behind the plateau uplift, whereas lithospheric detachment and slab abruption brought about quick uplift and subsequent extension of the plateau.

Geoscientists have done much in the study of the Qinghai-Tibet Plateau based on geophysical exploration, however, no thorough understanding has been gained. There are still disagreements with respect to many significant scientific issues. The plateau is so huge and complex that much more research needs to be done before we can get a clear geological picture.

\section{Acknowledgements}

We wish to thank Wang Chunyong, Zhang Zhongjie, Chen Zhiliang and Fang Shengming for their assistance and advice. Thanks are also due to Teng Jiwen, who provided us with data and study findings he obtained in 1958. We sincerely thank Liu Xinzhu, Wang Huaxiao and Zhang Zhaoyuan for their careful revision of the English. This paper was financed by the National Natural Science Foundation of China (No. 40334035) and the Ministry of Land and Resources of China (No. 200010101).

\section{References}

Bird, P., 1978, Initiation of intracontinental subduction in the Himalayas: J. Geophys. Res., 83: pp.4975 4987.

Chang, C.F., Pan, Y.S., Zheng, X.L., and Zhang, X.M.,1982, The geological tectonics of Qinghai-Xizang (Tibet) Plateau, China Science Press.

Chen, L.S., Booker, J.R., Jones, A.G., Wu, N., Unsworth, M.J., Wei, W.B., and Tan, H.D., 1996, Electrically conductive crust in southern Tibet from INDEPTH magnetotelluric surveying: Science, 274, pp.1694 1696.

Chen, G.Y. and Zeng, R.S., 1985, The difference of lithospheric structure between Himalayan mountain and Tibetan plateau from surface wave dispersion: Acta Geophysica Sinica (in Chinese), 28 (Suppl.), pp.161 173.

Cui, Z.Z., Li, Q.S., Wu, Ch.D., Yin, Z.X., and Liu, H.B., 1995, The crustal and deep tectonics in Golmud-Ejin Qi GGT: Chinese Journal of Geophysics (in Chinese), 38 (Suppl. a), pp.15 28

Gao, R. and Wu, G.J., 1995, Geophysical model and geodynamic process of Yadong-Golmud geoscience transect on Qinghai-Tibet plateau: Journal of Changchun University of Earth Sciences (in Chinese), 25(3), pp.241 250.

Gao, R., 1997, Thirty problems of the lithospheric structure and geodynamics on the Qinghai-Xizang plateau: Geological Review (in Chinese), 43(5), pp.460 464.

Gao, R., Huang, D.D., Lu, D.Y., Qian, G.H., Li, Y.K., Kuang, C.Y., Li, Q.S., Li, P.W. Feng, R.J., and Guan, Y. 2000, Deep seismic reflection profile across the contact zone of the West Kunlun orogenic belt and the Tarim Basin: Chinese Science Bulletin (in Chinese), 45(17), pp.1874 1879.

Gao, R., Li, P.W., Li, Q.S., Guan, Y., Shi, D.N., Kong, X.R. and Liu, H.B., 2001, Deep process of the collision and deformation in northern Tibetan Plateau-implications from deep seismic sounding results. Science in China (Series D) (in Chinese), 31(Suppl.), pp.66 71.

Gao, R., Ma, Y.S., and Zhu, X., 2005, The Lithospheric structures of the Songpan block in the northeastern Tibetan plateau-revelation from investigation of the deep seismic profile: GEOLOGIE ALPINE, 20th HimalayanKarakoruam-Tibet Workshop Special extended abstracts, Aussois France, pp.44.

Guo, B., Liu, Q.Y., Chen, J.H., Zhao, D.P., Li, S.C., and Lai, Y.G., 2004, Seismic tomographic imaging of the crust and upper mantle beneath the Northeastern edge of the Qinghai-Xizang plateau and the Ordos area: Chinese Journal of Geophysics (in Chinese) , 47(5), pp.790 797.
Guo, X.F., Zhang, Y.C., Cheng, Q.Y., Gao, R., and Pan, Y., 1990, Magnetotelluric studies along Yadong-Golmud geosciences transect on QinghaiXizang plateau: Bulletin of The Chinese Academy of Geological Sciences (in Chinese), 21, pp.191 202

Hirn, A., Lepine, J.C., Jobert, T.G., Sapin, M., Wittlinger, G., Xu, Z.X., Gao, E.Y., Wang, X.J., Teng, J.W., Xiong, S.B., Pandey, M.R., and Talte, J.M., 1984, Crust structure and variability of the Himalayan border of Tibet. Nature, 307(5946), pp.23 25.

Institute of Geophysics, Academic Sinica, 1981, Explosion seismic study for velocity distribution and structure of the crust and upper mantle from Damxung to Yadong of Xizang plateau. Acta Geophysica Sinica (in Chinese), 24(2), pp.155 170.

Jiang, M., Lu, Q.T., and Xue, G.Q., 1994, Research on crustal structure of the Tibetan Plateau using seismic experiment jointly by Chinese and French geophysicists: Chinese Journal of Geophysics (in Chinese), 37(3), pp.412 413.

Jiang, M., Lu, Q.T., and Shi, D.N., 1996, The study on the structure of crustal and upper mantle with natural earthquakes on central Tibetan Plateau: Chinese Journal of Geophysics (in Chinese), 39(4), pp.470 482.

Kao, H., Gao, R., Rau, R,J., Chen., R.Y, Shi, D.N., Chen, W.P., and Wu, F.T., 2001 , Seismic image of the Tarim basin and its collision with Tibet: Geology, 29(7), pp.575 578.

Kosarev, G., Kind, R., Sobolev, S.V., Yuan, X., Hanka, W. and Oreshin, S., 1999, Seismic evidence for a detached Indian lithospheric mantle beneath Tibet: Science, 283, pp.1306 1309.

Kind, R., Ni, J., Zhao, W.J. Wu, J.X., Yuan, X.H., Zhao, L.H., Sandvol, E., Reese, C., Nabelek, J., and Hearn, T., 1996, Evidence from earthquake data for a partially molten crustal layer in Southern Tibet: Science, 274 , pp.1692 1694.

Kind, R., Yuan, X., Saul, J., Nelson, D., Sobolev, S.V., Mechie, J., Zhao, W., Kosarev, G., Ni, J., Achauer, U., and Jiang, M. 2002, Seismic images of crust and upper mantle beneath Tibet: evidence for Eurasian plate subduction: Science, 298, pp.1219 1221.

Li, Q.S., Lu, D.Y., Gao, R., Zhang, Z.Y., Liu, W., Li, Y.K., Li, J.W., Fan, J.Y., and Xiong, S.M., 2001, An integrated study of deep seismic sounding profile along Xinjiang Global Geoscience Transect (Quanshuigou-Dushanzi): Acta Geoscientia Sinica (in Chinese ), 22(6), pp.534 540.

Li, Q.S., Peng, S.P., and Gao, R., 2004a, A review on the Moho discontinuity beneath the Tibetan plateau. Geological Review (in Chinese), 50(6), pp.598 612

Li, Q.S., Peng, S.P., Gao, R., Guan, Y. and Fan, J.Y., 2004b, Deep tectonic background of the 8.1 Ms earthquake in the east Kunlun: Acta Geoscientica Sinica (in Chinese), 25(1), pp.11 16.

Li, S.L., Zhang, X.K., and Zhang, C.K., 2002, A preliminary study on the crustal velocity structure of Maqin-Lanzhou-Jingbian by means of deep seismic sounding profile: Chinese Journal of Geophysics (in Chinese), 45(2), pp.210-217.

Li, T.D., 1995, The uplifting process and mechanism of the Qinghai-Tibet plateau: Acta Geoscientia Sinica (in Chinese), (1), pp.1-9.

Lithosphere Research Center of CAGS, 1996, Lithospheric structure and tectonics in Tibet and its formation and evolution. In: Geological Special, China : Geological Publishing House.,.20, pp.83 93

Liu, H.B., Kong, X.R., Ma, X.B., Wang, Q.S., Yan, Y.L., Yan, Y.F., and Yang, Z.Q., 2001, Crustal structure characteristics of southeastern Tibet: Science in China (Series D) (in Chinese), 31(Suppl.), pp.61-71.

Lu, D.Y., Huang, L.Y., Chen, J.P., Li, X.P., Hu, A.B., Wang, Y.Z., Wang, Z.C. Liu, W.T., and Zhang, Z.Y., 1990, Structural model and velocity dispersion characteristics of the crust and upper mantle in Tuotuohe-Golmud region of north Qinghai-Xizang plateau, in Geophysical Memoir on Xizang-Qinghai Plateau, China Geological Publishing House, pp.51-62.

Lü, Q.T., Jiang, M., and Ma, K.Y., 1996, 3-D travel time tomography inversion and the deep structure of southern Tibet: Acta Seismologica Sinica (in Chinese), 18(4), pp.451-459

Ma, X.B., Kong, X.R. and Yu, S., 1997, Magnetotelluric sounding in western Tibet. Chinese Science Bulletin (in Chinese) , 42(11) : 1185-1187.

Ma, X.B., Kong, X.R., Liu, H.B., and Yan, Y.L., 2001, Magnetotelluric sounding results in eastern Tibetan Plateau: Science in China (Series D) (in Chinese), 31 (Suppl.), pp.72-76.

McNamara, D.E., Owens, T.J., and Walter, W.R., 1995, Observations of the regional phase propagation across the Tibetan Plateau: Journal of Geophysical Research, 100(22), pp.22215-22229.

Meng, L.S., Shen, J.S., Qi, L., Zhang, F.H., Zhang, L., Wu, L.G., Meulebrouck, J., and Tarits, P., 1984, The preliminary interpretation of the gravity profile of well Yang No.8, Nielamu, Tibet: Geophysical Prospecting for Petroleum (in Chinese), 23(2), pp.1-21

Meng, L.S., Gao, R., Zhou, F.X., Li, L., and Wang, H.X., 1990a, Intepretation of the crustal structure in Yadong-Golmud area using gravity anomalies: Bulletin of The Chinese Academy of Geological Sciences (in Chinese), 21, pp.149-161. 
Meng, L.S., Jiang, X.R., Zhang, F.H., and Xian, E.D., 1990b, Gravity profile and the crustal structure of Yecheng-Shiquanhe: Acta Geophysica Sinica (in Chinese), 33(6), pp.670 677.

Meng, L.S., Guan, Y., Qi, L., and Gao, R., 1995, Gravity field and deep crustal structure in Golmud-Ejin Qi geoscience transect and nearby area: Chinese Journal of Geophysics (in Chinese), 38 (Suppl.a), pp.36-45.

Meng, L.S., Qi, L., Gao, R., and Chen, Y.M., 1998, Gravity survey and isostatic message along the profile of Aergan (in Xinjiang)-Laomangya (in Qinghai): Journal of Changchun University of Science and Technology (in Chinese), 28(3), pp.345 350.

Murphy, M.A., Yin, A., Harrison, T.M., Dürr, S.B., Chen, Z., Ryerson, F.J., Kidd, W., Wang, X., and Zhou, X., 1997, Did the Indo-Asian collision alone create the Tibetan plateau: Geology, 25(8), pp.719-722.

Nelson, K.D., Zhao, W.J., Brown, L.D., Kuo, J., Che, J.K., Liu, X.W., Klemperer, S.L., Marovsky, Y., Meissner, R., Mechie, J., Kind, R., Wenzel, F., Ni, J., Nabelek, J., Chen, L.S., Tan, H.D., Wei, W.B., Jones, A.G., Booker, J., Unsworth, M., Kidd, W., Hauck, M., Alsdorf, D., Ross, A., Cogan, M.,Wu, C.D., Sandvol, E., and Edwards, M., 1996, Partially molten middle crust beneath Southern Tibet: Synthesis of project INDEPTH results: Science, 274, pp.1684-1688

Pan, Y.S., 1999, Formation and uplifting of the Qinghai-Tibet plateau: Earth Science Frontiers (in Chinese), 6(3), pp.153-163.

Pelkum, S., Monsalve, G., Sheehan, A., Pandey, M.R., Sapkota, S., Bilham, R., and $\mathrm{Wu}, \mathrm{F} .2005$, Imaging the Indian subcontinent beneath the Himalaya: Nature, 435, pp.1222-1225.

Qian, H., Jiang, M., Xue, G.Q., and Su, H.P., 2001, Crustal structure of eastern Tibet inferred from natural earthquake receiver function analysis: Acta Seismological Sinica (in Chinese), 23(1), pp.103-108.

Qin, G.Q., Chen, J.H., Liu, D.J., Gu, Q., and Xiong, Y.W., 1994, The characteristics of the electrical structure of the crust and upper mantle in the region of the Kunlun and Karakorum mountains: Acta Geophysica Sinica (in Chinese), 37(2), pp.193-199.

Ross, A., Brown, L., Passakorn, P., Nelson, K.D., Klemperer, S., Haines, S., Zhao, W.J., and Guo, J.R., 2004, Deep reflection surveying in central Tibet: lower-crustal layering and crustal flow: Geophysical Journal International, 156, pp.115-128

Shen, X.J., Zhang W. R., Yang, S.Z., Guan, Y., and Jin, X., 1990, Heat flow evidence for the differentiated crust-mantle thermal structures of the Qinghai-Xizang plateau: Bulletin of the Chinese Academy of Geological Sciences (in Chinese), 21, pp.203-214

Shen, X.J., Yang, S.Z., and Shen, J.Y., 1995, Heat flow study and analysis along the Golmud-Ejin Qi geotransect: Acta Geophysica Sinica (in Chinese), 38 (Suppl.II), pp. 86-97.

Shi, D.N., Jiang, M., Ma, K.Y., Xue, G.Q., Dong, Y.J., Poupinet, G., Wittlinger, G., and Herquel, G., 1999, Crust and upper mantle tomographic structure across the Altyn fault zone using teleseismic p-waves. Chinese Journal of Geophysics (in Chinese), 42(3), pp. 341-350.

Song, Z.H., An, C.Q., Wang, C.Y., Chou, Z.R., and Zhang, L.J., 1985, The Pwave velocity of upper mantle beneath Qinghai-Tibet plateau and northsouth seismic zone: Acta Geophysica Sinica (in Chinese), 28(Suppl.), pp $148-160$

Spratt, J.E., Jones A.G., Nelson, K.D., Unsworth, M.J., and INDEPTH-MT Team., 2005, Crustal structure of the India-Asia collision zone, southern Tibet, from INDEPTH MT investigations: Physics of the Earth and Planetary Interiors, pp.1-11.

Sun, J., Jin, G.W., Bai, D.H., and Wang, L.F., 2003, Electrical structure of the crust and upper mantle and tectonics sense on the edge of the East Tibet. Science in China(Series D) (in Chinese), 33(Suppl.), pp.173-180

Tan, H.D., Wei, W.B., Unsworth, M. Deng, M., Jin, S., Booker, J., and Jones, A., 2004, Crustal electrical conductivity structure beneath the Yarlung Zangbo suture in the southern Xizang plateau, Chinese Journal of Geophysics (in Chinese), 47( 4), pp.685-690.

Teng, J.W., 1974, Deep reflected waves and the structure of the earth crust of the eastern part of Qaidam basin: Acta Geophysica Sinica (in Chinese), 17(2), pp. 121-134.

Teng, J.W., Xiong, S.B., Yin, Z.X., Xu, Z.X., Wang, X.T., and Lu, D.Y., 1983, Structure of the crust and upper mantle pattern and velocity distributional characteristics in the Northern Himalayan mountain region: Acta Geophysica Sinica (in Chinese), 26(6), pp.525-540.

Teng, J.W., Yin, Z.X., and Xiong, S.B., 1985, Crustal structure and velocity distribution beneath Selin Co-Peng $\mathrm{Co}-\mathrm{Na}$ Qu-Suo County region in northern Xizang plateau: Acta Geophysica Sinica (in Chinese), 28(Suppl.), pp. $28-42$.

Teng, J.W., Zhang, Z.J., Wang, G.J., Liu, H.B., Hu, J.F., Zhang, B.M., Chen, Y., and Zhang, H., 1999, The deep internal dynamical processes and new model of continent-continent collision in Himalayan collision orogenic zone: Chinese Journal of Geophysics (in Chinese), 42(4), pp.481-494.

Tilmann, F., Ni, J., and INDEPTH Seismic Team, 2003, Seismic imaging of the down-welling Indian lithosphere beneath central Tibet, Science, 300, pp. 1424-1427.
Wang, C.Y., Wu, J.P., and Lou, H., 2003a, Crustal P-wave velocity structure in western Sichuan and eastern Tibet: Science in China (Series D) (in Chinese), 33(Suppl.), pp.181-189

Wang, C.Y., Han, W.B., Wu, J.P., Lou, H., and Bai, Z.M., 2003b, Crustal structure beneath the Songpan-Garze orogenic belt: Acta Seimologica Sinica, 16(3), pp.237-250.

Wang, Q.S., Wu, C.Z., and Wang, W.W., 1997, Gravity field and crustal structure of Jilong-Lugu region in western Tibet: Chinese Science Bulletin (in Chinese), 42(8), pp.858-862.

Wang, Q.S. and An, Y.L., 2001, Gravity field and deep structure of MadoiShama region in eastern Qinghai-Xizang(Tibetan) plateau: Process in Geophysics (in Chinese), 16(4), pp.4-10.

Wang, S., Lu, D.Y., Huang, L.Y., Li, X.P. and Hirn, A., 1990, Velocity distribution characteristics and N-S variation of the depth of the earth's crust in the Xizang (Tibet) plateau: Geophysical Memoir on Xizang-Qinghai plateau (in Chinese), China Geological Publishing House, pp. 38-47.

Wang, Y.X. and Qian, H. 2000, Study of crustal velocity structure in the east Qinghai. Earth Science Fronties(in Chinese), 7(4) : 568-579.

Wei, W.B., Unsworth, M., Jones, A., Booker, J., Tan. H.D, Nelson, D., Chen, L.S., Li, S.H., Solon, K., and Bedrosian, P., 2001, Detection of widespread fluids in the Tibetan crust by magnetotelluric studies: Science, 292, pp 716-718.

Wittlinger, G., Vergne, J., Tapponnier, P., Farra, V., Poupinet, G., Jiang, M., $\mathrm{Su}, \mathrm{H}$., Herquel, G., and Paul, A., 2004, Teleseismic imaging of subducting lithosphere and Moho offsets beneath western Tibet: Earth and Planetary Science Letter, 221, pp. 117-130.

Wu, G.J., Gao, R., Yu, Q.F. Cheng, Q.Y., Meng, L.S., Dong, X.B., Cui, Z.Z., Yin, Z.X., Shen, X.J., and Zhou., Y.X., 1991, Intergrated investigations of the Qinghai-Tibet plateau along the Yadong-Golmud geoscience transect: Acta Geophysica Sinica (in Chinese), 34(5), pp. 552-562.

Wu, J.P., Ming, Y.H., Ye, T.L., and Zeng, R.S., 1998, Upper mantle velocity structure in the Qinghai-Xizang Plateau from inversion of body waveforms: Acta Geophysica Sinica (in Chinese), 41(Suppl.), pp.15-25.

Wu, Q.J. and Zeng, R.S., 1998, The crustal stucture of Qinghai-Xizang plateau inferred from broadband teleseismic waveform: Acta Geophysica Sinica (in Chinese), 41(5), pp.669-679.

Wu, Q.J., Zeng, R.S., and Zhao, W.J., 2004, Dipping structure of upper mantle and continent-continent collision in Himalayas-Tibet Plateau: Science in China (Series D) (in Chinese), 34(10), pp.919-925.

Wu, X.Z., Wu, C.L., Lu, J., and Wu, J. 1995, Research on the fine crustal structure of the northern Qilian-Hexi Corridor by deep seismic reflection: Chinese Journal of Geophysics (in Chinese), 38(Suppl.II), pp.29-35.

Xiong, S.B., Teng, J.W., and Yin, Z.X., 1985, The thickness of the crust and undulation of discontinuity in Xizang (Tibet) plateau: Acta Geophysica Sinica (in Chinese), 28(Suppl.), pp.16-27.

Xiong, S.B. and Liu, H.B., 1997, Crustal structure in the western Tibetan plateau: Chinese Science Bulletin (in Chinese), 42(12), pp. 1309-1312.

Xu, X. Z., Qi, X. F., Yang, C. L., and Dang, S.J, Results of man-made explosion seismic sounding from Huashixia (in Qinghai) to Aksay (in Gansu) Annual of the Chinese Geophysical Society. China: Seismological Press 1993 , pp.80.

Xu, Z.Q., Yang, J.S., and Jiang, M., 2001, Collision-orogeny of the northern Qinghai-Tibet plateau and its deep dynamics: Acta Geoscientia Sinica (in Chinese), 22(1), pp.5-10.

Xu, Z.Q., Jiang, M., Yang, J.S., Xue, G.Q., Su, H.P., Li, H.B., Cui, J.W., Wu, C.L., and Liang, F.H., 2004, Mantle structure of Qinghai-Tibet plateau: Mantle plume, mantle shear zone and delamination of lithospheric slab, Earth Science Frontiers (in Chinese ), 11(4), pp.329-343

Xue, G.Q., Jiang, M., and Su, H.P., 2004, A study on deep structure of Yecheng-Shiquanhe region on Tibetan plateau by tomographic imaging: Science in China (Series D) (in Chinese ), 34 (4), pp.329-334.

Yin, A., 2001, Geologic evolution of the Himalayan-Tibtan orogen-Phanerozoic growth of Aisa continetal: Acta Geoscientia Sinica (in Chinese), 22(3), pp.193-230.

Yu, Q.F., Sun, Y.S., Lou, H.,Li, Q.X., and Lu, Q.T., 1990, The magnetic structure of geoscience transect from Yadong to Golmud: Bulletin of The Chinese Academy of Geological Sciences (in Chinese), 21, pp.183-190.

Yu, Q.F., Lou, H., and Hu, Z.D., 1995, Magnetic data interpretation of the crustal structure of the geoscience transect from Golmud to Ejin Qi: Chinese Journal of Geophysics (in Chinese), 38 (Suppl.II), pp.58-70.

Yuan, X.C., Li, L., Jin, G.Y., Feng, Y.P., Zhu, J.H., Lu, G., Phan, V.N., Boyer, D., Therme, P., and Miel, J.L., 1990, Magnetotelluric investigations in Lhozang-Sangxung area, Tibet, in Geophysical Memoir on Xizang-Qinghai Plateau, China Geological Publishing House, pp.63-71.

Zeng, R.S. and Gan, R.J., 1961, Reflected waves from crustal interface in western Qaidam Basin: Acta Geophysica Sinica (in Chinese), 10(1), pp.120125.

Zeng, R.S., Wu, F., and Owens,.J.T., 1992, Introduction of Sino-American Project "Study of geodynamics and structure of crust and upper mantle of 
the Qinghai-Tibet Plateau: Acta Seismologica Sinica (in Chinese), 14 (Suppl.), pp.521-522.

Zeng, R.S., Ding, Z.F., and Wu, Q.J. 1994, A review of the lithospheric structures in Tibetan plateau and constraints for dynamics: Acta Geophysica Sinica (in Chinese), 37 (Suppl.), pp.99-116.

Zeng, R.S., Ding, Z.F., and Wu, Q.J., 1998, The crustal structure from Himalaya to Qilian and its implications for continent-continent collision process. Chinese Journal of Geophysics (in Chinese), 41(1), pp.49-60.

Zeng, R.S., Ding, Z.F., Wu, Q.J., and Wu, J.P., 2000, Seismological evidence for the multiple income crustal subductions in Himalayas and southern Tibet. Chinese Journal of Geophysics (in Chinese), 43(6), pp.780-797.

Zhang, Z.J., Li, Y.K., Wang, G.J., Teng, J.W., Klemplerer, S., Li, J.W., Fan, J.Y., and Chen, Y., 2001, E-W Crustal stucture under the northern Tibet and 'down-bowing' Moho under the northern Tibet revealed by wideangle seismic profile. Science in China (Series D) (in Chinese), 31(11), pp.881888.

Zhang, Z.J., Teng, J.W.,Li, Y.K., Klemperer, S., and Yang, L.Q., 2002, Crustal velocity structure and eastward escaping of crustal material in the southern Tibet. Science in China (Ser. D) (in Chinese), 32(10), pp.793-798.

Zhao, J.M. , Zhang, X.K., Wang, S.X., Lu, B., Zhang, J., and Lu, M.A., 2001, The lithospheric structure and dynamic process of the Junggar Basin, the Tianshan Orogenic Belt, the Tarim Basin, the Altun Orogenic Belt, the Qaidam Basin, and the Kunlun Orogenic Belt (northern margin), in Chinese Geophysical Society, ed, Annual of the Chinese Geophysical Society, pp.13.

Zhao, J.M., Zhang, X.K., Deng, H.Z., and Zhang, J., 2003, Q value structure of the upper crust along the profile from Baicheng to Da Qaidam: Chinese Journal of Geophysics (in Chinese): 46(4), pp.503-509.

Zhao, W.J., Nelson, K.D., and Project INDEPTH Team, 1993, Deep seismic reflection evidence for continental underthrusting beneath southern Tibet, Nature, 366(9), pp.557-559

Zhao, W.J., Nelson, K.D., and Meissner, R., 1997, Advances of INDEPTH-A deep profiling study in Tibet and the Himalayas: Episodes, 20(4), pp.266272.

Zhao, W.J., Mechie, J., Brown, L.D., Guo, J., Haines, S., Hearn, T., Klemperer, S.L. Ma Y. S., Meissner, R., Nelson, K. D , Ni, J.F. Pananont, P., Rapine, R., Ross, A., and Saul, J. 2001, Crustal structure of central Tibet as derived from INDEPTH wide-angle seismic data: Geophysical Journal International, 145. pp.486-498

Zhao, W.J., Xue G.Q., Zhao, X., Wu, Z.H., Shi, D.N. Liu, K., Jiang, W., Xiong, J.Y., and INDEPTH Team, 2004, Seismic imaging of the subducting Indian lithosphere beneath northern Tibet: Acta Geoscientia Sinica (in Chinese), 25(1), pp.1-10

Zhong, D. L. and Ding L., 1996, Research on the uplift process and mechanism of the Tibetan plateau: Science in China (Series D) (in Chinese), 26(4), pp. 289-295

Zhu, L.P., and Helmberger, D.V., 1998, Moho offset across the northern margin of the Tibetan plateau: Science, 281,1170-1172.

Zhu R.X. and Hu X.Y., 1995, Study on the resistivity structure of the lithosphere along the Golmud-Ejin Qi geoscience transect: Chinese Journal of Geophysics (in Chinese), 38(Suppl.II), pp.46-57.

Zhuang, Z., Fu, Z.W., Lu, Z.L., Hu, J.F., Song, Z.H., Chen, G..Y., An, C.Q., and Chen, L.H., 1992, 3-D shear velocity model of crust and upper mantle beneath the Tibetan plateau and its adjacent regions: Acta Geophysica Sinica (in Chinese), 35(6), pp.694-709.
Rui Gao is director of Lithosphere Research Center, CAGS. He received his Master degree in Geophysics from Changchun College of Geology. His primary research interests are geophysical probes, continental lithospheric structure and geodynamics. Since 1984, he has been actively investigating the structure of the crust and upper mantle beneath the Tibet plateau. He was one of the leading scientists of several global transects during 1991-2000. He is a Council member of the Chinese Geophysical Society and of the Chinese Society of Tibet Plateau Research. He is also a member of geophysical expert groups of the National Nature Science Foundation of China.

Zhanwu Lu, Ph.D. at Institute of Geology, Chinese Academy of Geological Sciences. Received his Master of Science degree from the College of Geoexploration science and technology, Jilin University in 2003. His research focuses on deep geophysical studies in lithospheric structure and geodynamics beneath the QinghaiTibet plateau.

Qiusheng Li received his B.Sc. in geophysics from Changchun College of Geology and his Ph.D. in geophysics from China University of Mining and Technology. He has been actively involved in geophysical studies in Qinghai-Tibet plateau and adjacent regions since $1992 . t$ His major research interests are geophysical surveys, lithospheric structure, formation of the QinghaiTibet plateau and its implications on environments and resources. He has participated in numerous regional and international cooperative projects
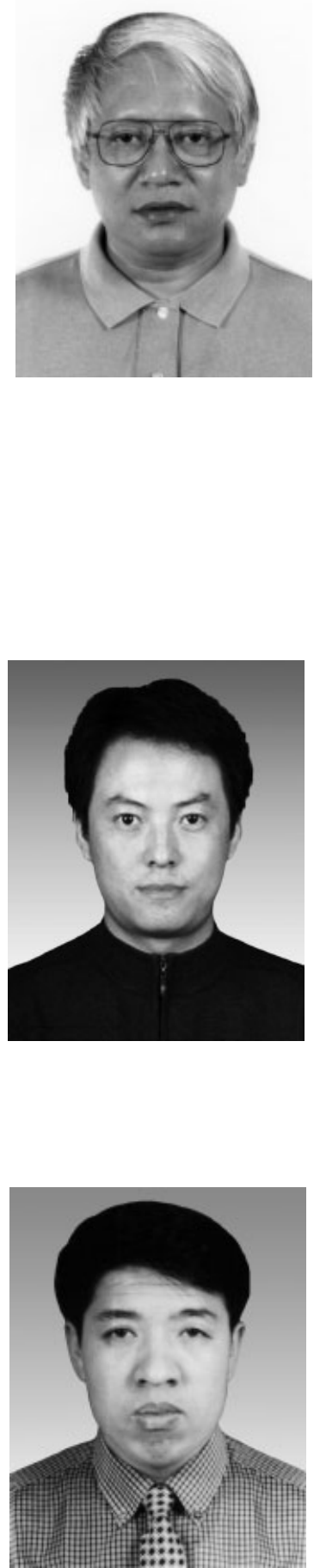